\title{
Erratum to: Prevalence of HIV Risk Behaviors Between Binge Drinkers and Non-Binge Drinkers Aged 18- to 64-Years in US, 2008
}

\author{
Xiao-Jun Wen $\cdot$ Lina Balluz $\cdot$ Machell Town
}

Published online: 12 February 2012

(C) Springer Science+Business Media, LLC 2012

Erratum to: J Community Health (2012) 37:72-79

DOI 10.1007/s10900-011-9418-y

Unfortunately, there is a typo in the line 11 of the "Abstract" section. It is incorrectly published as "among binge bingers" in the original publication of both online and print version. It should read as "among binge drinkers".

In addition, the affiliation for all the authors have been updated with this erratum.

The online version of the original article can be found under doi:10.1007/s10900-011-9418-y.

X.-J. Wen $(\bowtie) \cdot$ L. Balluz $\cdot$ M. Town

Division of Behavioral Surveillance, Public Health Surveillance

Program Office, Office of Surveillance, Epidemiology, and

Laboratory Services, Centers for Disease Control and

Prevention, 1600 Clifton Road NE, Mailstop E-97,

Atlanta, GA 30333, USA

e-mail: tzw4@cdc.gov

L. Balluz

e-mail: lib74@cdc.gov

M. Town

e-mail: mpt2@cdc.gov 